\title{
Correction to: Statistics and Empirical Knowledge
}

\section{Correction to:}

Chapter 3 in: G. Arbia, Statistics, New Empiricism and Society in the Era of Big Data, SpringerBriefs in Statistics, https://doi.org/10.1007/978-3-030-73030-7_3

The original version of this chapter was inadvertently published with two incorrect Figures 3.1 and 3.2, which have now been updated. The book has been updated with the changes. 

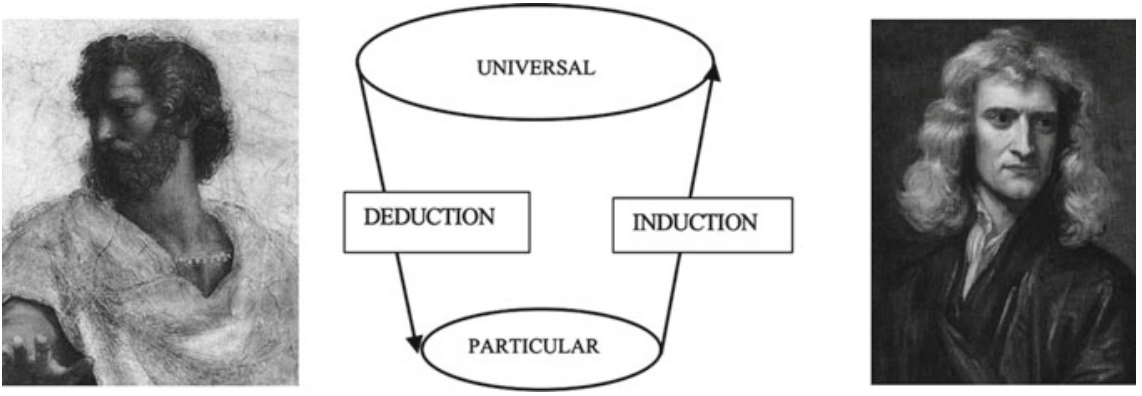

Fig. 3.1 Two basic procedures to reach knowledge: Deduction and Induction

Fig. 3.2 Deduction and induction in the statistical terminology

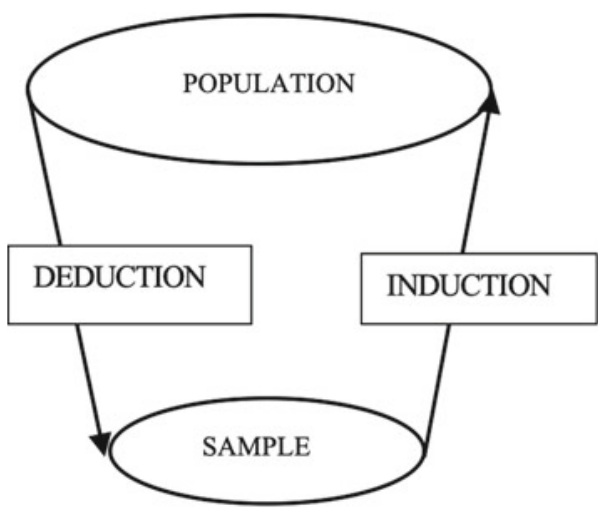

